\title{
A IRONIA SituACIONAL na Poesia de Emily Dickinson
}

Situational irony in Emily Dickinson's poetry

\author{
Carlos Daghlian *
}

A ironia de situação ou situacional, geralmente citada como uma forma que se opõe à ironia verbal, poderia ser também chamada de comportamental, pois o ironista pode servir-se de outros meios, além da palavra, para transmitir significados como, por exemplo, um sorriso, um gesto, uma pintura ou uma música. Mas, como ela tem a intenção de transmitir significados, podemos ficar com a já consagrada expressão "ironia verbal".

Por ironia de situação entendemos a que se observa num estado de coisas ou num determinado acontecimento. Ao contrário do que ocorre com a ironia verbal, a de situação não transmite o significado irônico; este é captado pelo observador, embora sempre possa haver sugestões de realidades encobertas por aparências. Neste caso, o ironista torna-se irônico por apresentar situações a serem percebidas pelos outros. Este tipo de ironia também se faz presente na obra poética de Dickinson.

\begin{tabular}{|c|c|}
\hline $\begin{array}{l}\text { If pain for peace prepares } \\
\text { Lo, what "Augustan" years } \\
\text { Our feet await! }\end{array}$ & $\begin{array}{l}\text { Se a dor para a paz prepara } \\
\text { Então, que anos "Augustos" } \\
\text { Nossos pés esperam! }\end{array}$ \\
\hline $\begin{array}{l}\text { If springs from winter rise, } \\
\text { Can the Anemones } \\
\text { Be reckoned up? }\end{array}$ & $\begin{array}{l}\text { Se as primaveras surgem do inverno, } \\
\text { Podem as Anêmonas } \\
\text { Ser contadas? }\end{array}$ \\
\hline $\begin{array}{l}\text { If night stands first - then noon } \\
\text { To gird us for the sun, } \\
\text { What gaze! }\end{array}$ & $\begin{array}{l}\text { Se a noite vigora primeiro - depois a } \\
\text { tarde } \\
\text { Para envolver-nos de sol, } \\
\text { Que olhar! }\end{array}$ \\
\hline $\begin{array}{l}\text { When from a thousand skies } \\
\text { On our developed eyes } \\
\text { Noons blaze! }\end{array}$ & $\begin{array}{l}\text { Quando de mil céus } \\
\text { Em nossos olhos desabrochados } \\
\text { As tardes resplandecem! }\end{array}$ \\
\hline J 63 / F 155 & Trad. Carlos Daghlian (1987, p. 206-207) \\
\hline
\end{tabular}


Em "If pain for peace prepares", Dickinson estabelece um contraste entre a miséria humana na terra e a glória celestial após o sofrimento:

o poema define uma felicidade espetacular, contrastando-a com $o$ estado em que a narradora se encontra (JUHASZ, 1977, p. 107). A tranquilidade indescritível que a imortalidade proporciona recompensa uma vida de renúncia limitada por escuridão e cegueira (CODY, 1971, p. 433).

A terceira estrofe encerra o ponto central do poema e, por sua vez, o efeito da palavra "olhar" contém a chave da estrofe. Além de referir-se à imagem visual, o ato de olhar faz-se acompanhar das emoções que ele próprio desperta (PORTER, 1981, p. 148). A luz celeste que se projeta equivale em termos metafóricos à realização no amor, como em outros poemas de Dickinson.

"For each ecstatic instant" pode ser considerado como uma versão um tanto alterada do conceito emersoniano da compensação:

\begin{tabular}{|c|c|}
\hline $\begin{array}{l}\text { For each ecstatic instant } \\
\text { We must an anguish pay } \\
\text { In keen and quivering ratio } \\
\text { To the ecstasy. }\end{array}$ & $\begin{array}{l}\text { Por todo instante de êxtase } \\
\text { nós pagamos angústia } \\
\text { em proporção aguda } \\
\text { e trêmula ao nosso êxtase. }\end{array}$ \\
\hline $\begin{array}{l}\text { For each beloved hour } \\
\text { Sharp pittances of years - } \\
\text { Bitter contested farthings- } \\
\text { And Coffers heaped with Tears! }\end{array}$ & $\begin{array}{l}\text { Por toda hora querida } \\
\text { severas rações de anos, } \\
\text { cousas vãs disputadas, } \\
\text { cofres cheios de pranto. }\end{array}$ \\
\hline J 125 F 109 & Trad. Abgar Renault (1994, p. 33) \\
\hline
\end{tabular}

o poema declara que o ser humano tem, para cada êxtase que vivencia, uma parcela de sofrimento a experimentar. Mas Dickinson ironiza a ideia de Emerson quando julga que o sofrimento com que pagamos pelo êxtase é maior, ou seja, considera o preço do êxtase alto e exorbitante (POLLAK, 1984, p. 110). A ironia de situação está baseada em contrastes.

Dickinson vê a compensação, portanto, como uma força negativa, pois o sofrimento apresenta-se como uma consequência natural do êxtase e esta inter-relação das duas experiências manifesta-se como uma condição própria do mundo em que vivemos. A atitude irônica diante de tal situação é a melhor forma de defesa que Dickinson encontra para evitar surpresas ou decepções. Por isso, Dickinson, "reagindo ironicamente à experiência, aprende a olhar com igual favor para as contradições e possibilidades conflitantes que a cercam" (GRIFFITH, 1964, p. 44), conseguindo distanciar-se delas.

$\mathrm{O}$ acúmulo progressivo de imagens nos três últimos versos do poema sugere a extensão da dor com que se paga pelo êxtase (ALEXANDER, 1965, p. 66). Por um momento de felicidade, pagamos com agonia intensa. Assim como o Getsêmane ocorre com mais frequência do que o Éden na poesia de Dickinson, a agonia também é mais comum do que o êxtase. Mas, 
no fim, permanece a pergunta: "Por que devemos pagar com tanta dor por um momento de êxtase?"

"Water, is taught by thirst." mais uma vez desenvolve um dos temas recorrentes na poesia de Dickinson:

\begin{tabular}{|l|l|}
\hline $\begin{array}{l}\text { Water, is taught by thirst. } \\
\text { Land - by the Oceans passed. }\end{array}$ & A água se ensina pela sede; \\
Aransport - by throe - & A terra, por oceanos navegados; \\
O êxtase, pela aflição; & -by its battles told- \\
$\begin{array}{l}\text { Love, by Memorial Mold - } \\
\text { Birds, by the Snow. }\end{array}$ & $\begin{array}{l}\text { O amor, pelos combates narrados; } \\
\text { E, pela neve, os pássaros. }\end{array}$ \\
J 135 F 93 & Trad. Ivo Bender (2002, p. 83) \\
\hline
\end{tabular}

Tudo que o homem aprende resulta de algum tipo de desintegração que, por sua vez, representa a morte (CHASE, 1951, p. 123). O ser humano só capta o sentido profundo das coisas mediante a carência e a distância.

As grandes experiências humanas só são valorizadas pelo conhecimento dos opostos; neste caso, sente mais a necessidade quem já teve fartura e esta, melhor a compreende quem não a tem. $O$ penúltimo verso concentra a ironia do poema: uma oposição implica a outra.

A ironia de situação em "To learn the Transport by the Pain" criase inicialmente por um aparente contraste de tom entre o início e o fim do poema:

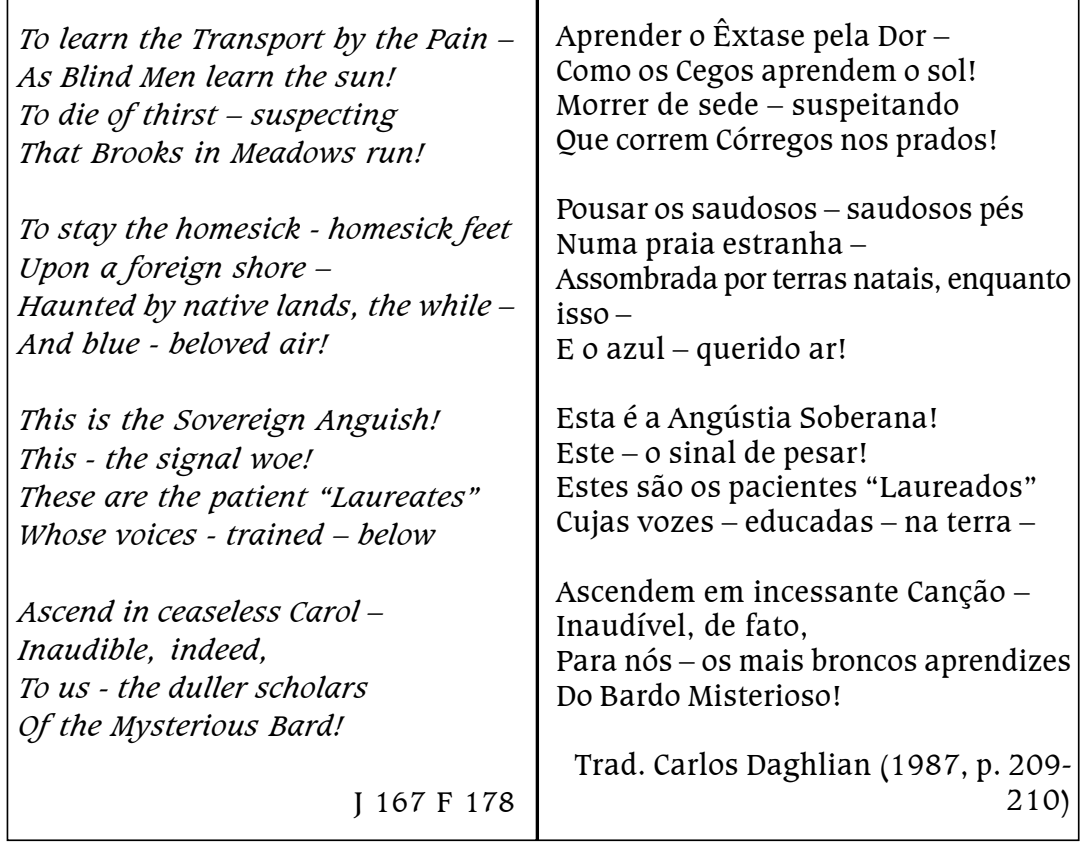


O tom inicial torna-se declamatório, mas o poema termina em desespero e resignação. Como em outros poemas complexos, Dickinson mantém suspense do inicio ao fim em virtude da promessa de imortalidade com que acena, afirmando que apreciamos e sentimos melhor o êxtase do ângulo privilegiado da dor (CODY, 1971. p. 434).

A primeira estrofe diz que só quem passa por necessidades pode encontrar satisfação. Os dois últimos versos são como que uma ressalva dos dois primeiros, cuja afirmação categórica se relativiza no terceiro e quarto, pois o verbo "aprender" do início sugere alguma certeza, enquanto "suspeitar" deixa certa dúvida. "Aprender" e "suspeitar" indicam, portanto, dois níveis de conhecimento, o definitivo e o provável, o que se julga ter e o que se suspeita ter, o que se confia ter e o que se desconfia ter (PORTER, 1981, p. 132). A felicidade interior só se alcança pela experiência do sofrimento e da tristeza. Temos aqui mais uma vez o processo antitético característico de Dickinson, pois, para definir a felicidade, ela primeiro imagina o seu oposto.

A poeta sente saudades de "terras natais" que, estando no plural, reforçam a ambiguidade segundo a qual a expressão estaria se referindo à vida futura no céu, "uma praia estranha", bem como à vida secular neste mundo. Tal duplicidade de sentido remete-nos mais uma vez aos dois níveis de conhecimento, o real (vida presente) e o suspeitado (vida futura), isto é, o secular e o religioso. Ao fim da segunda quadra, fica determinado o conhecimento secular.

Os "Laureados" aqui' "em baixo" têm a missão de "recuperar a realidade primordial do ser" (KHER, 1974, p. 103); só eles sabem como superar a "Angústia Soberana", a partir da experiência do sofrimento. Os poetas dão aqui uma lição de fé. As aspas de "Laureados" indicam também a ambiguidade deste título; tanto pode estar se referindo aos que receberam a graça de Deus por coroa, como aos próprios poetas, cuja glória consiste em outro tipo de imortalidade. Mais uma vez o aspecto secular justapõe-se ao religioso.

A "incessante Canção" da poeta, uma canção de sofrimento, tornase "inaudível" aos "mais broncos aprendizes", os poetas da terra, que resistem ao encontro com o precursor de todos os poetas, Deus, o "Bardo Misterioso" (DIEHL, 1981, p. 102). Assim, "os mais broncos aprendizes" rejeitam o único caminho capaz de levar à fonte da existência, ficando somente com a dor da vida terrena.

Se na primeira metade do poema Dickinson privilegiou a visão secular da existência, na segunda ela tomou o rumo da fé, mostrando que a segurança dos que aceitaram a condição religiosa passa despercebida aos "mais broncos aprendizes". A poeta, entretanto, parece estar apenas observando as duas situações, e dizendo que tudo a vida nos ensina.

Em "I lost a World " the other day!" verificamos o simbolismo típico de Dickinson: 


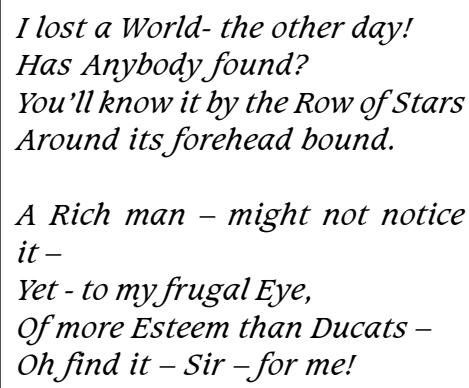

J 181 F 209
Um Mundo perdi - há dias! Será que Alguém o encontrou? Por um Diadema de Estrelas, Se conhece onde ficou.

Um Rico - nel' não repara -

Mas é de tanto Valor

Para os meus olhos frugais

Procurai-mo - por favor!

Trad. Jorge de Sena (1978, p. 87)

o poema não permite clara interpretação. Assim, a expressão "Diadema de Estrelas" pode estar se referindo à coroa de espinhos de Cristo, que seria o "mundo" perdido.

A ironia surge no início da segunda quadra, quando a poeta tenta avaliar a perda segundo os critérios de um homem rico. Foi provavelmente esta ironia que levou Porter (1981, p. 85) a observar a quebra do sentido elegíaco do poema.

Há um contraste na própria estrutura do poema. Enquanto a primeira estrofe se caracteriza pela força e originalidade de pensamento e de expressão, a segunda, que manifesta a ironia, não foge ao lugar comum.

A exemplo do que faz em outros poemas, em "I can wade Grief" Dickinson primeiro relata uma experiência, para dar-lhe depois um caráter universal (HOWARD, 1966, p. 64). Assim, a primeira estrofe trata do caso particular da narradora e a segunda aborda uma situação representativa, generalizando em termos de experiência humana.

\begin{tabular}{|c|c|}
\hline $\begin{array}{l}\text { I can wade Grief- } \\
\text { Whole Pools of it - } \\
\text { I'm used to that - } \\
\text { But the least push of Joy } \\
\text { Breaks up my feet - } \\
\text { And I tip - drunken- } \\
\text { Let no Pebble - smile- } \\
\text { 'Twas the New Liquor- } \\
\text { That was all! }\end{array}$ & $\begin{array}{l}\text { Na dor eu passo a vau - } \\
\text { Charcos inteiros - } \\
\text { Questão de hábito. } \\
\text { Mas um leve esbarro de aleqria } \\
\text { Me embaralha os pés, } \\
\text { Perco o equilíbrio - ébria. } \\
\text { Que nenhum seixo se ria - } \\
\text { Bebida inédita - } \\
\text { É só isto! }\end{array}$ \\
\hline $\begin{array}{l}\text { Power is only Pain - } \\
\text { Stranded, thro' Discipline, } \\
\text { Till Weights - will hang - } \\
\text { Give Balm - to Giants - } \\
\text { And they'll wilt" like Men - } \\
\text { Give Himmaleh - } \\
\text { They'll Carry - Him! }\end{array}$ & $\begin{array}{l}\text { A força não é mais que dor } \\
\text { No encalhe da disciplina } \\
\text { Até suportar mais fardos. } \\
\text { Dêem bálsamo a gigantes } \\
\text { E - como homens - } \\
\text { Fracos, vergam. } \\
\text { Dêem-lhes o Himalaia - } \\
\text { Eles O carregam! } \\
\text { Trad Aíla de Oliveira Gomes }(1985, \text { p. } 55)\end{array}$ \\
\hline
\end{tabular}


A poeta desenvolve e dramatiza a ideia de que a dor e o sofrimento são experiências benéficas e saudáveis ao homem, por meio de comparações entre a dor e o prazer em todo o poema, argumentando a favor do sofrimento; segundo ela, este pode ser tolerado com maior facilidade, o que vem a ser irônico e paradoxal.

"O Teste" (ou "A Provação"), título dado ao poema pelos primeiros editores de Dickinson, inclui-se entre os poemas de "inspiração" bíblica, em que as Escrituras funcionam como fonte de sugestões, pois a poeta parte destas, para distorcer ou criar novas imagens, que se distanciam das origens a ponto de, às vezes, não deixar vestígios aparentes. Em outras palavras, ela faz a sua "revisão" de alguns textos bíblicos; nesses casos, então, a Bíblia constitui-se em mero estímulo ou pretexto para sua poesia.

As duas estrofes interligam-se por meio de contrastes e paralelos, que vão desde a forma até as ideias e imagens.

Temos, na primeira estrofe, imagens relativas ao estado líquido e, na segunda, ela fala da dor (e não da fé) que pode mover montanhas, "adaptando" assim a proposição bíblica. A primeira estrofe contém várias alusões bíblicas que indicam a intenção de transmitir o que seria a "boanova", a mensagem principal (ou primeira) da poeta. Tais alusões têm a ver com algum início importante tanto no Velho como no Novo Testamento. Wolff (1986, p. 215) lembra duas passagens de Gênesis, a Criação (a vida surgindo das águas) e o Dilúvio (a morte causada pela água e o reinício da vida humana), e duas dos Evangelhos, o vinho da última Ceia e a afirmação de Cristo segundo a qual não se coloca vinho novo em odre velho; daí a expressão "Bebida Inédita". Juhasz (1984, p. 97), por sua vez, observa que esta estrofe contrasta a água do sofrimento com o vinho da alegria, remetendo-nos ao milagre das Bodas de Caná, quando Cristo transformou água em vinho para a alegria dos convivas. O verso "Que nenhum seixo se ria - ", ainda que remotamente, associa-se à advertência de Cristo com relação a atirar a primeira pedra e, com os dois anteriores, lembra-nos de Pedro perdendo o equilíbrio quando andava sobre as águas, em sua primeira ousadia.

As sugestões de "primeira vez", somadas umas às outras, reforçam a impressão de que Dickinson pretendia anunciar com ênfase uma ideia que lhe era muito cara e que julgava fundamental: os efeitos positivos do sofrimento na vida humana. Assim, para introduzir um de seus principais temas, ela se vale de vários indícios bíblicos na primeira estrofe.

$\mathrm{Na}$ primeira estrofe, a narradora esbarra na alegria, que pode tirar-lhe a disciplina; na segunda, os gigantes poderão ficar fracos e vergar, se receberem algum bálsamo. Em outras palavras, a luta de vadear, representando a disciplina da vida diária, na primeira, equivale ao sofrimento como disciplina da segunda. O seixo, representando os pequenos obstáculos da vida rotineira, pela sua insignificância, contrasta com a montanha portentosa no final do poema (CODY, 1978, p. 15). Temos então que a pessoa comum, da primeira estrofe, e os gigantes sobre-humanos, da segunda, 
reagem de maneira idêntica a estímulos semelhantes: aquela vadeia nos charcos, estes carregam montanhas. Como diz Wolff (1986, p. 215), "a estratégia do poema é manter forças destrutivas e criativas em tensão, demonstrando que o bem pode surgir de um mal aparente [...]".

Para realçar o seu pensamento, Dickinson combina a métrica com o sentido. O contraste começa pela disparidade do número de versos de cada estrofe; a antecipação de rima que se frustra auxilia nossa compreensão da ironia do poema, cuja métrica desordenada acompanha os efeitos do sofrimento (LAIR, 1971, p. 42). Dickinson rompe os limites do hino religioso e de quaisquer outros esquemas métricos convencionais, que seriam os "odres velhos", incapazes de conter o "vinho novo" de sua inebriante poesia. A métrica cambaleante acompanha o cambaleio dos pés da narradora, pois os "pés" do quinto verso estão "claudicando" em virtude da sugestão de alegria, que provoca falha no movimento métrico. Se compararmos o esquema métrico das duas estrofes, veremos que a métrica mais desordenada da primeira acompanha o ziguezigue da narradora inebriada pela nova bebida, ao passo que a disciplina proposta na segunda reflete-se no esquema mais ordenado desta: (primeira) / $\mathrm{x} / / / \mathrm{xx} \mathrm{x} / \mathrm{x} / \mathrm{xx} / / / \mathrm{x} / \mathrm{xx} / / \mathrm{x}(/)(\mathrm{x}) / / / \mathrm{x} / \mathrm{xx} / / \mathrm{x}(/)$ (x) $/ \mathrm{x} /$ (segunda) $/ \mathrm{xx} / \mathrm{x} / / \mathrm{xx} / \mathrm{x} / \mathrm{x} / \mathrm{x} / / / \mathrm{x} / \mathrm{x}(/) \mathrm{xx} / \mathrm{x} / \mathrm{x} / \mathrm{x} / \mathrm{x} / \mathrm{x} /$ (LAIR, 1971, p. 43).

Deste modo, Dickinson procura apresentar o sofrimento como um "mestre" que transmite conhecimentos, ensina habilidades e incute o senso de disciplina (CODY, 1978, p. 16), pois, para ela, a dor é condição sine qua non para as realizações de mérito. Nesse contexto, ela dramatiza a ideia de que a felicidade debilita e a adversidade fortalece o ser humano.

Em "'Hope' is the thing with feathers", um de seus poemas de definição, Dickinson tenta dar uma explicação concreta para um termo abstrato.

\begin{tabular}{|c|c|}
\hline $\begin{array}{l}\text { "Hope" is the thing with } \\
\text { feathers- } \\
\text { That perches in the soul- } \\
\text { And sings the tune without the } \\
\text { words - } \\
\text { And never stops - at all - } \\
\text { And sweetest - in the Gale - is } \\
\text { heard - } \\
\text { And sore must be the storm - } \\
\text { That could abash the little Bird } \\
\text { That kept so many warm - } \\
\text { I've heard it in the chillest land- } \\
\text { And on the strangest Sea- } \\
\text { Yet, never, in Extremity, } \\
\text { It asked a crumb-of Me. } \\
\text { J } 254 \text { F } 314\end{array}$ & $\begin{array}{l}\text { A esperança é um ente com penas } \\
\text { Que na alma pousa. } \\
\text { E entoando cantigas sem palavras } \\
\text { Jamais repousa. } \\
\text { O seu canto é mais doce em pleno } \\
\text { vento. } \\
\text { Só a violenta procela é que arrefece } \\
\text { E intimida o pequenino pássaro } \\
\text { Que a tantos aquece. } \\
\text { Nos mares mais estranhos eu o vi } \\
\text { E em terras geladas. } \\
\text { Contudo mesmo em situações } \\
\text { extremas } \\
\text { Jamais me pediu nada. } \\
\text { Trad. Idelma Ribeiro de Faria } \\
\text { (1992, p. } 117)\end{array}$ \\
\hline
\end{tabular}


A ideia de esperança vem expressa de forma concreta, como um pássaro que canta alegre, mesmo em circunstâncias as mais desfavoráveis e sem esperar qualquer recompensa. No tempo de Dickinson eram comuns os emblemas que representavam a figura de Cristo como um pássaro, o que pode explicar a espiritualidade e abnegação desta ave personificada (WOLFF, 1986, p. 478).

Por meio de uma metáfora irônica que surge logo na primeira estrofe e que se estende ao poema todo, tornando-se a sua sustentação, Dickinson define a atitude ambivalente de quem espera sem esperança, mas que observa, com reverência e espanto, um pássaro real no plano do espírito, mas que não tem existência física (GOUDIE ${ }^{1}$, apud DUCHAC, p. 163).

A ironia está em que a pessoa que vive a esperança não sabe explicar por quê, pois trata-se de mero sentimento, uma melodia na alma que a abriga.

O poema "There's a certain Slant of light" revela a preocupação de Dickinson com o efeito de certos fenômenos naturais no mundo interior do indivíduo:

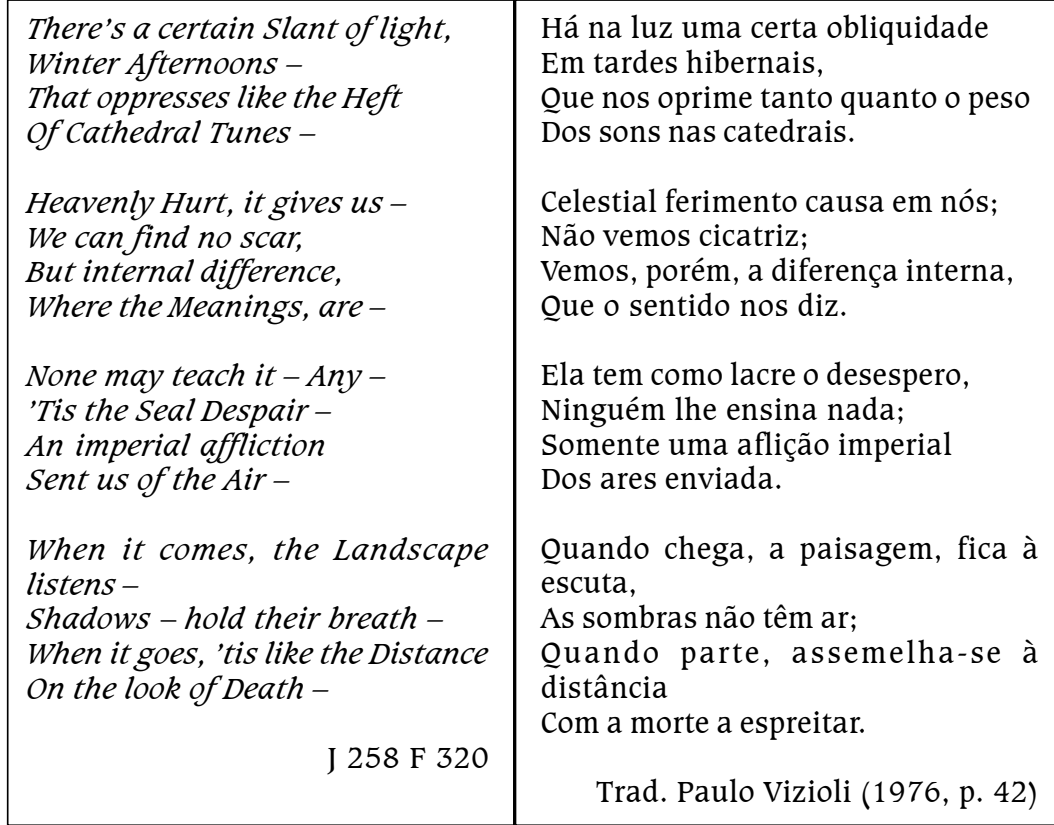

Há um símile irônico já nos dois últimos versos da primeira quadra. A obliquidade na luz pode representar a presença de Deus, como sugerem as expressões "sons nas catedrais", "celestial ferimento" e "aflição

${ }^{1}$ GOUDIE, Andréa. Another Path to Reality: Emily Dickinson's Birds. Concerning Poetry, 7, n. 1, p. 31-38, Spring 1974. 
imperial". As imagens do poema constituem-se de elementos da natureza e da igreja, que servem para dar ou sugerir a sensação da morte. O inverno que oprime ameaça a fé, pois as diversas associações religiosas aprofundam o desespero e sugerem que a luz representa um teste ou uma prova para a alma.

À natureza, ela atribui qualidades humanas oriundas dela própria como poeta, a ponto de sugerir a irrelevância da realidade objetiva da natureza. A morte metaforiza a luz de inverno e vice-versa. As figuras do poema aplicam-se à vida interior; a rigor nada tem a ver com o inverno ou com a luz; tentam definir uma realidade interior, não uma realidade física.

O poema todo tenta definir uma depressão estranha e muito pessoal. O estado de depressão exprime-se por palavras como oprime, peso, ferimento, desespero, aflição e ar da morte (PERRINE, 1964, p. 34). O poema relacionase com a explicação psicanalítica de um tipo passageiro de depressão, que se manifesta na atmosfera distinta criada pelo crepúsculo. A como que mortal atmosfera da tarde hibernal impõe à poeta a consciência de sua inexorável despedida. É a sua resposta a um certo momento da natureza em que um raio de luz cria uma atmosfera de tristeza numa tarde de inverno. $O$ portador da "aflição imperial" causada pelo "desespero" está como que dotado da fortaleza e da compaixão próprias dos que, embora nobres, estão perturbados e feridos. A partir da descrição da luz hibernal o poema torna-se "um depoimento sobre a natureza do desespero e do isolamento." (ALEXANDER, 1965 , p. 105). A imagem do desespero apresenta-se como "uma certa obliquidade na luz", ao pôr do sol de uma tarde hibernal, enfatizando a qualidade amorfa do sofrimento. A luz hibernal traz o desespero porque também nos lembra da ameaça da morte. Somente vivendo em desespero pode-se experimentar a liberdade do desespero.

o paradoxo central do poema está na ideia de que nos sentimos mais vivos quanto mais forte for a nossa "percepção" da morte. As características e os efeitos do desespero são o tema central do poema, que não tem outro tema que não "a tristeza dolorosa da pálida tarde hibernal." (BALDI, 1960, p. 440).

Além de evocar um estado de espírito, o poema tenta explicá-lo. Definir a experiência torna-se a maior dificuldade do poema, cuja tendência parece ser o abandono da metáfora a favor da metonímia.

A tentativa de conciliar a natureza com a morte indica ajustamento antes que desespero. Está implícita mais uma morte psíquica do que a morte física. É morrendo para as coisas deste mundo que se estabelece um relacionamento maduro com o macrocosmo.

o poema constitui-se num conjunto de contrários que atuam uns sobre os outros. As opções espirituais e psicológicas ficam em aberto. A ironia está em que o significado da momentânea obliquidade da luz reside no seu desaparecimento (SHERWOOD, 1968, p. 97), ou seja, ela ilumina a possibilidade das trevas. E esta ironia abrange o poema como um todo, 
passando a ter nele uma função totalizante.

A partir de um clichê, a velha comparação da vida com um relógio, e da crendice segundo a qual o relógio para quando seu dono morre, Dickinson compara a morte à quebra irreparável de um relógio suíço de boa qualidade:

\begin{tabular}{|c|c|}
\hline $\begin{array}{l}\text { A Clock stopped- } \\
\text { Not the Mantel's - } \\
\text { Geneva's farthest skill } \\
\text { Can't put the puppet bowing- } \\
\text { That just now dangled still- }\end{array}$ & $\begin{array}{l}\text { O Relógio parou - } \\
\text { Não o de cima da Lareira - } \\
\text { A habilidade mais requintada de Genebra } \\
\text { Não pode fazer curvar o fantoche - } \\
\text { Que neste instante dependura-se rijo - }\end{array}$ \\
\hline $\begin{array}{l}\text { An awe came on the Trinket! } \\
\text { The Figures hunched, with pain - } \\
\text { Then quivered out of Decimals - } \\
\text { Into Degreeless Noon - }\end{array}$ & $\begin{array}{l}\text { Um espanto surgiu no Adorno! } \\
\text { Os Algarismos arquejaram, de dor- } \\
\text { Depois deixaram os Decimais tremendo- } \\
\text { E entraram no Grau Zero do Meio-Dia - }\end{array}$ \\
\hline $\begin{array}{l}\text { It will not stir for Doctors - } \\
\text { This Pendulum of snow - } \\
\text { This Shopman importunes it - } \\
\text { While cool - concernless No- }\end{array}$ & $\begin{array}{l}\text { Ficará impassível diante de Médicos - } \\
\text { Este Pêndulo de neve - } \\
\text { O Relojoeiro o importuna - } \\
\text { Enquanto frio - indiferente Não - }\end{array}$ \\
\hline $\begin{array}{l}\text { Nods from the Gilded pointers - } \\
\text { Nods from the Seconds slim- } \\
\text { Decades of Arrogance between } \\
\text { The Dial life- } \\
\text { And Him - }\end{array}$ & $\begin{array}{l}\text { Meneios dos ponteiros Dourados - } \\
\text { Meneios dos esbeltos Segundos - } \\
\text { Décadas de Arrogância entre } \\
\text { A vida do Mostrador - } \\
\text { E Ele - }\end{array}$ \\
\hline $\mathrm{J} 287 \mathrm{~F} 25$ & Trad. Carlos Daghlian (1985, p. 5) \\
\hline
\end{tabular}

o poema estrutura-se segundo o equilíbrio criado pelo contraste entre as duas primeiras estrofes, que tratam do aspecto físico da morte, e as duas últimas, que consideram inúteis os esforços do médico no sentido de recuperar a vida.

O meio-verso que inicia o poema enfatiza a repentina cessação da vida e do tempo, e a insignificância do ser humano acentua-se quando ele é comparado a um objeto mecânico. Então, pouca consolação resta. A primeira estrofe diz-nos que o relógio acabou de parar, que uma pessoa acabou de morrer e que o movimento não será renovado. Evoca, pois, um senso de repentina imobilidade, decorrente da morte, com expressões que indicam a perda da tensão e do tom da vida: "curvar o fantoche", "dependura-se rijo".

$\mathrm{Na}$ segunda estrofe, observamos o ato de morrer pelos olhos de quem observa o relógio. $\mathrm{O}$ moribundo, tomado de temor reverente, percebe que está morrendo; ao sentir no rosto os estertores da morte, os ponteiros assinalam meio-dia e a morte chega. Volta-se, pois, ao momento que precede a morte e sugere que a impossibilidade de se conhecer a realidade da própria morte é uma das ideias centrais do poema. Aqui intensifica-se a "sensação" de imobilidade.

As duas primeiras estrofes tratam, portanto, do momento da morte e dos instantes que a precedem. 
Na terceira, a imobilidade do corpo morto intensifica-se ainda mais e se desenvolve o efeito da completa falta de reação da morte. O início desta sugere que, uma vez parado o relógio da vida, o restante do poema falará do pós-morte. Mas não é o que acontece, pois pela segunda vez a poeta nos dá uma visão dos momentos em que o relógio da vida vai deixando de trabalhar. O médico e o relojoeiro nada conseguem junto ao morto, a não ser um "não" indiferente, que se estende à última estrofe, como que indicando um esforço no sentido de recuperar o movimento.

As duas últimas estrofes tratam da frustração do "médico" na tentativa de restaurar a vida. Dickinson ironiza aí as limitações do poder de Deus. O pêndulo congelado a repetir "não" sugere o desespero diante da morte, ou seja, a desintegração de um sistema lógico de crenças diante do maior mistério que o ser humano tem diante de si, a morte (PICKARD, 1967, p. 108). Estas estrofes desviam a nossa atenção dos mortos para o esforço inútil dos vivos para recuperar uma vida que se foi para sempre. O "não" (no) da terceira estrofe, que ressoa nos "meneios" (nods) da quarta, vem a ser a negativa enfática dada ao relojoeiro que tenta restaurar a vida. A expressão "pêndulo de neve" traz um dos símbolos favoritos de Dickinson, a neve, para exprimir a condição da morte como algo branco e gelado. "Décadas de Arrogância" indica o peso sobrepujante da eternidade e é a grande barreira posta entre a vida e a morte.

A imagem do relógio suíço controla o poema todo. Genebra, além de importante centro da indústria relojoeira, era a residência de Calvino. A morte na metáfora do relógio parado lembra-nos da irremediabilidade da morte física e insinua a "ineficácia" da doutrina calvinista.

Este poema contém quase todas as boas qualidades da notável poesia de Dickinson sobre a ars moriendi. Para dizer que os mortos vislumbram o céu na hora da morte, ela usa a palavra; "temor" (awe) e, para definir a barreira intransponível entre a alma e sua breve vida anterior, a separação absoluta que temia, a palavra "Arrogância", na expressão "Décadas de Arrogância", é a que sua sensibilidade julga mais oportuna.

Com sutileza, o poema todo combina a realidade desesperadora da morte física, e as espantosas limitações da vida temporal, com o mistério da eternidade. Ele contém uma hipérbole marcante: "O médico se desdobra para reativar as batidas do coração, o pêndulo frio e imóvel do defunto, mas o morto resiste com arrogância aos melhores esforços de restauração" (WARREN, 1970, p. 83). Os pés trocaicos no início dos três primeiros versos da última estrofe sugerem os meneios excêntricos ou desgovernados do corpo morto. Ironicamente, o poder do Fantoche-mor mostra-se ineficaz.

O trocadilho contido em figures (= figuras / algarismos) relacionase ao conceito do relógio como um todo e se expande em "deixaram os Decimais tremendo".

Embora não seja uma metáfora consoladora da eternidade, "o grau zero do meio-dia" sugere o caráter atemporal da eternidade, ou seja, o momento em que o relógio completa o ciclo e o sol está mais brilhante. A 
morte, porém, não traz glória nem segurança. Dickinson ironiza o mortal, que é surpreendido em sua plenitude, ao meio-dia. Conforme observa Ferlazzo (1976, p. 48),

com azedume ela talvez esteja sugerindo que nós somos como os adornos do relógio. Como os bonecos que se curvam parodiando cortesia e que repetidamente executam suas insignificantes e orgulhosas rotinas, somos levados a fazer o mesmo por algum fabricante de bonecos, até que a morte nos congele e exponha o absurdo de nossa conduta. (FERLAZZO, 1976)

Para Anderson (1960, p. 237), as figuras do médico, do relojoeiro e do fabricante de relógios podem ser consideradas como "máscaras do Grande Artífice, com uma ironia que se aproxima da blasfêmia". E acrescenta a explicação de que "o Senhor dá e o Senhor tira, mas não pode repetir o ato com o mesmo adorno".

“Temos aqui uma fina ironia”, diz Miner (1966, p. 58), e conclui:

O "boneco" sempre se curvava a partir da cabeça ou da cintura para marcar as horas. Agora, entretanto, o relógio finalmente acena para o "grau zero do meio-dia" com frios "não". Enquanto o algarismo acena apenas com aquela negação que é a morte, ele nega o pedido do "relojoeiro" para que o relógio continue. (MINER, 1966)

"I'll tell you how the Sun rose" inicia-se, já no primeiro verso, com uma promessa de explicação:

\begin{tabular}{|c|c|}
\hline $\begin{array}{l}\text { I'll tell you how the Sun rose- } \\
\text { A Ribbon at a time-- } \\
\text { The Steeples swam in Amethyst- } \\
\text { The news, like Squirrels, ran - } \\
\text { The Hills untied their Bonnets - } \\
\text { The Bobolinks - begun - } \\
\text { Then I said softly to myself- } \\
\text { "That must have been the Sun"! } \\
\text { But how he set - I know not- } \\
\text { There seemed a purple stile } \\
\text { That little Yellow boys and girls } \\
\text { Were climbing all the while- } \\
\text { Till when they reached the other side, } \\
\text { A Dominie in Gray - } \\
\text { Put gently up the evening Bars-- } \\
\text { And led the flock away-- }\end{array}$ & $\begin{array}{l}\text { Vou-te contar como é que O sol nasceu: } \\
\text { De repente uma fita apareceu, } \\
\text { Campanários nadaram em ametista } \\
\text { E notícias correram como esquilos; } \\
\text { Colinas desataram seus toucados, } \\
\text { Os passarinhos romperam em trinados. } \\
\text { Então disse baixinho p'ra mim mesma, } \\
\text { 'Deve ter sido o Sol'! } \\
\text { Mas como foi que ele se pôs, não sei } \\
\text { dizer. } \\
\text { No céu, um torniquete avermelhado- } \\
\text { Meninos e meninas de amarelo } \\
\text { Pulavam por ali em atropelo, } \\
\text { Na pressa de alcançar o outro lado- } \\
\text { Quando um clérigo de hábito cinzento } \\
\text { Fez o gradil da noite subir manso-- } \\
\text { E dispersou o bando. } \\
\text { Trad. Aíla de Oliveira Gomes (1984, } \\
\text { p. 65) }\end{array}$ \\
\hline
\end{tabular}


O poema se divide em duas partes, com duas estrofes cada uma. Na primeira cria-se a expectativa do desvendamento de um mistério que, ao invés de ser revelado na segunda, acentua-se ainda mais. A expectativa criada com o verso "eu lhe direi como o sol nasceu" fica frustrada logo no primeiro verso da segunda parte; estabelece-se um contraste quando, referindo-se à maneira como o sol se pôs, Dickinson diz: "não sei dizer".

Depois de surpreendido pelo nascer do sol, a poeta descreve o pôr do sol de maneira contrastante: um mundo de conto de fadas em que crianças douradas percorrem um caminho de púrpura na direção do céu.

A aurora e o crepúsculo são personificados e descritos por metáforas e o poema desenvolve-se como uma canção de roda. Os verbos nadar, correr e pular, aí empregados, são descritivos de atividades humanas.

A ironia aparece nos componentes da imagem criada pela expressão “crianças amarelas", por causa do sol.

Em "This is my letter to the World", Dickinson mostra uma atitude ambivalente para com a fama e o reconhecimento público:

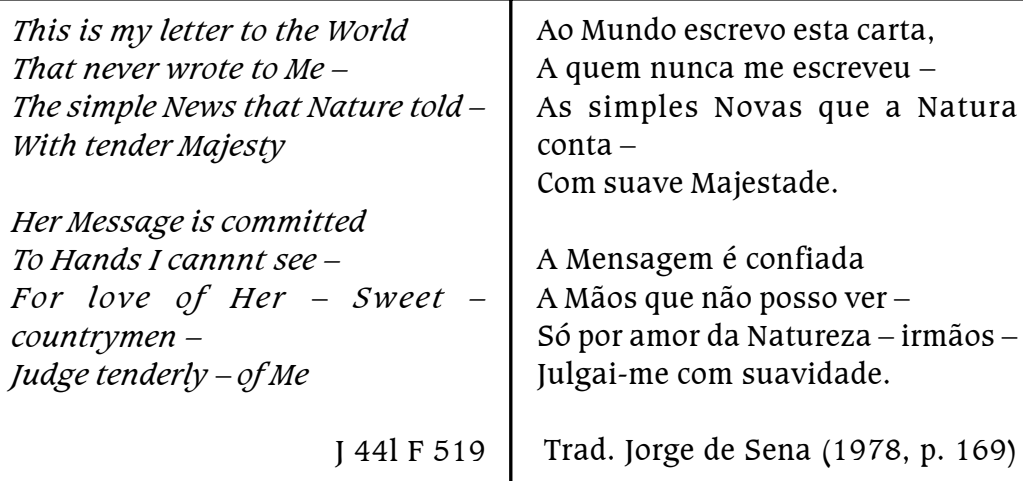

Esta "carta" que Dickinson escreveu ao mundo, equivalente a um manifesto poético, ela mesma não a enviou. Um dos motivos que a teriam levado a não publicar os seus poemas seria o receio de se expor à curiosidade pública, uma preocupação perfeitamente compreensível numa mulher do século dezenove; outro teria sido a consciência que tinha da peculiaridade de sua poesia e da dificuldade que sentia em transmitir a "Mensagem" da Natureza. (PORTER, 1981, p. 120) Mas, apesar de exigente consigo mesma, ela pode pressentir a consagração póstuma.

Afastar-se do mundo foi a maneira paradoxal que, como muitos grandes artistas, encontrou para dele se aproximar. (KHER, 1974, p. 65) De tal afastamento ela soube tirar a força espiritual necessária para escrever poemas como este, o meio que encontrou para falar com a posteridade, com o seu senso de vocação poética, como se estivesse entre nós. 
A súplica final do poema dá-lhe um toque de ironia, quando consideramos que Dickinson estava ciente das dificuldades que teria em conciliar o seu mundo de poeta com o mundo exterior.

"I heard a Fly buzz - when I died - " transforma uma situação trágica em grotesca:

\begin{tabular}{|c|c|}
\hline $\begin{array}{l}\text { I heard a Fly buzz-when I died- } \\
\text { The Stillness in the Room } \\
\text { Was like the Stillness in the Air } \\
\text { Between the Heaves of Storm- } \\
\text { The Eyes around-had wrung them } \\
\text { dry - } \\
\text { And Breaths were gathering firm } \\
\text { For that last Onset-when the King } \\
\text { Be witnessed - in the Room- } \\
\text { Iwilled my Keepsakes - Signed away } \\
\text { What portion of me be } \\
\text { Assignable-and then it was } \\
\text { There interposed a Fly- } \\
\text { With Blue - uncertain stumbling } \\
\text { Buzz- } \\
\text { Between the light-and me- } \\
\text { And then the Windows failed - and } \\
\text { then } \\
\text { Icould not see to see- }\end{array}$ & $\begin{array}{l}\text { Lembranças em testamento, leguei } \\
\text { De mim â porção que supus } \\
\text { Transferível - e foi então } \\
\text { Quando uma mosca se interpôs - } \\
\text { Com azul, indeciso, tropeçante } \\
\text { Zumbir - entre a luz e o meu ser - } \\
\text { Por fim falharam-me as janelas } \\
\text { E eu não podia ver para ver - } \\
\text { Trad. Aíla de Oliveira Gomes (1985, } \\
\text { p. } 79)\end{array}$ \\
\hline
\end{tabular}

Trata-se de mais um poema em que Dickinson imagina a própria morte, um exercício, que a fascinava. Em 1852, pouco mais de dez anos antes de fazê-lo, ela escreveu à amiga Jane Humphrey:

No outro dia tentei pensar como eu ficaria de olhos fechados, vestida de branco, com uma anêmona no peito, e imaginei ouvir os vizinhos entrando e saindo mansa e sorrateiramente, para verem o meu rosto - completamente adormecido - todo imóvel. (DICKINSON, 1965, p. 197)

Logo na primeira estrofe já nos vemos diante de uma situação irônica, porque o agonizante é quem observa tudo que se passa ao seu redor e não os vivos, como era de se esperar. A ironia intensifica-se ainda pelo tom neutro do agonizante, que se apresenta mais como observador do que como participante do evento da morte, cuja atmosfera se cria pelo silêncio no quarto e pelo zumbido da mosca. Isto sugere a audição como o único sentido que ainda lhe resta.

$\mathrm{Na}$ segunda estrofe o agonizante volta a atenção para os que presenciam sua morte. Com as lágrimas já esgotadas, eles também se preparam para encarar a morte. A aproximação da morte cada vez mais 
separa o agonizante do mundo sensorial, reduzindo-o à ação do intelecto.

Depois da separação psicológica do mundo, na terceira estrofe o agonizante faz a separação legal, quando assina o testamento, deixando seus bens aos herdeiros.

Nas três primeiras estrofes, portanto, o agonizante aos poucos se afasta do mundo dos sentidos.

Na última estrofe o momento da morte absorve a atenção do agonizante por meio do zumbido contínuo e azul da mosca, que acaba por escurecer o ambiente. Com o colapso total dos sentidos e da consciência, o zumbido da mosca ganha proporções gigantescas, pois passa a dominar a situação e o ambiente; a mosca, como que aumenta de tamanho e de força diante da fraqueza do agonizante. A escolha de um inseto tão comum e repugnante sugere a banalização de um momento tão importante como a hora da morte, mas a soma dos detalhes, culminando com a sinestesia expressa pelo "azul do zumbido", intensifica o sentido de tal momento: os olhos secos de tanto chorar, o rei poderoso entrando no quarto (a morte, como querem alguns, ou Deus, de acordo com o pensamento dos contemporâneos de Dickinson que acreditavam que, nessa hora, o agonizante via ou sentia a presença da Divindade), a enigmática "redundância" - "não poder ver para ver" - o desaparecimento da luz, tudo contribui para a visão total.

Este poema procura mostrar a distância que existe entre o espírito e os sentidos ou o corpo e a alma, até o desenlace desta (ALEXANDER, 1965, p. 69).

A chave da interpretação deste poema está na análise das reações humanas à presença da mosca, o único ser movente do poema, um inseto repugnante e incômodo que anuncia a morte, pois, sendo urna criatura que só anela por carne, simboliza todo o desdém pelas coisas do espírito. Ela pode ainda, de acordo com a tradição teológica em que Dickinson foi criada, ser considerada como emissário de satanás. (HOLLAHAN ${ }^{2}$, apud DUCHAC, 1979, p. 206)

Há no poema uma combinação e vários elementos para criar uma imagem completa da morte física, necessária à salvação pessoal.

Outra ironia vem da descoberta do que seria enfrentar a imortalidade, pois trata-se de uma experiência muito diferente daquela para a qual estamos preparados, uma experiência "ao mesmo tempo triunfante e horrível." (LYNEN ${ }^{3}$, apud DUCHAC, 1979, p. 205)

o zumbido azul da mosca lembra o uso que Shakespeare faz do azul como arauto da morte (CONNELLY ${ }^{4}$, apud DUCHAC, 1979, p. 206). Lembremos ainda que normalmente associamos a cor azul com o céu, um lugar que nem sequer se vislumbra neste poema, onde só "experiência e n. 1. Sept. 1966 , Item 6.

HOLLAHAN, Eugene. Dickinson's 'I heard a Fly buzz - when I died.' The Explicator , 25,

3 LYNEN, Jonh. F. Three Uses of the Present: The Historian's, The Critic's, and Emily Dickinson's. College English, 28, n. 2. p. 126-136. Nov. 1966

Item 34

${ }^{4}$ CONELLY, James. T. I heard a Fly buzz - when I died.'. The Explicator, 25, n. 4. Dec. 1966 
sensações predominam." (MOREY, 1974, p. 30)

A grande ironia do poema está em que o momento crucial da morte despoja-se de qualquer sinal de grandeza, pois, ao invés de um rei, vemos uma mosca, um inseto vil a lembrar que o cadáver será devorado por insetos como ela. (TODD 5 , apud DUCHAC, 1979, p. 209)

Da perspectiva do agonizante que, "num retrospecto antecipado" (FORD ${ }^{6}$, apud DUCHAC, 1979, p. 206), relata as próprias sensações diante da morte, os objetos, e não ele, vão aos poucos se desvanecendo. Então a mosca, o único ser que se move e se faz ouvir, torna-se o símbolo da morte individual em contraste com a morte pública, sendo um bom exemplo do realismo e da ironia de Dickinson.

A forma do poema também contribui para acentuar o aspecto irônico, pois a morte física, sem perspectiva de esperança, está expressa em estrofes que seguem o modelo do metro comum, com exceção das últimas rimas, que são imperfeitas. E a característica central da mosca, presente em todo o poema pelo seu zumbido, afirma-se pelo uso de sibilantes: buzz, stillneis, was, heaves, storm; uncertain, stumbling, buzz, see.

"I had been hungry, all the Years" mais uma vez dramatiza a ideia da superioridade do sofrimento sobre a satisfação:

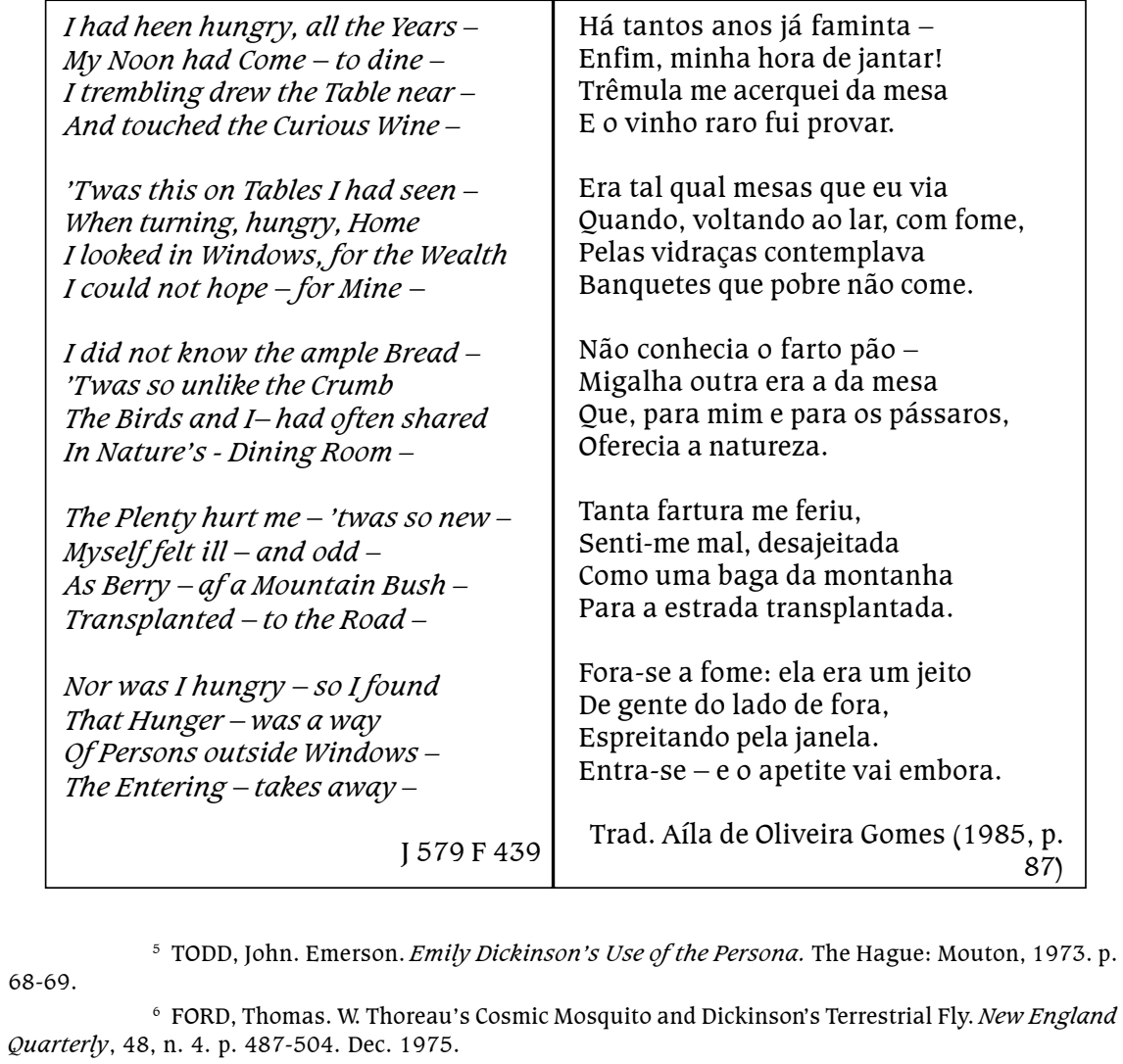

Há tantos anos já faminta Enfim, minha hora de jantar! Trêmula me acerquei da mesa E o vinho raro fui provar.

Era tal qual mesas que eu via Quando, voltando ao lar, com fome, Pelas vidraças contemplava Banquetes que pobre não come.

Não conhecia o farto pão Migalha outra era a da mesa Que, para mim e para os pássaros, Oferecia a natureza.

Tanta fartura me feriu, Senti-me mal, desajeitada Como uma baga da montanha Para a estrada transplantada.

Fora-se a fome: ela era um jeito De gente do lado de fora, Espreitando pela janela.

Entra-se - e o apetite vai embora.

Trad. Aíla de Oliveira Gomes (1985, p.

${ }^{5}$ TODD, John. Emerson. Emily Dickinson's Use of the Persona. The Hague: Mouton, 1973. p. ${ }^{6}$ FORD, Thomas. W. Thoreau's Cosmic Mosquito and Dickinson's Terrestrial Fly. New England Quarterly, 48, n. 4. p. 487-504. Dec. 1975. 68-69. 
Nas três primeiras estrofes a narradora fala do longo período de privação pelo qual tem passado e da possibilidade de satisfação que finalmente lhe chegou; nas duas últimas explica a recusa de tal oportunidade.

Dickinson usa a fome como "estratégia estética" (MOSSBERG, 1983, p. 60) para descrever a irrealização amorosa e a rejeição dos valores sociais que abomina. Ela experimenta o vinho, mas não come o pão; comê-lo seria aceitar as regras da sociedade que está rejeitando. Por terem conotações sacramentais, o pão e o vinho cercam a possibilidade da relação amorosa com urna aura de santidade (CODY, 1971, p. 139).

Habituada a compartilhar migalhas com os pássaros, assusta-se com a fartura. A fome deixou-a revoltada (hunger/anger) e desconfiada. A hora de comer torna-se dolorosa ao invés de lhe dar prazer. A atitude da poeta aqui assemelha-se à de Fernando Pessoa, quando ele diz: "Até amaria o lar, desde que o não tivesse". (PESSOA, 1960, p. 346)

Como "uma baga da montanha" a narradora sente-se deslocada ao se encontrar na estrada; prefere permanecer no estado anterior de privação. Basta-lhe testemunhar a satisfação dos outros do lado de fora.

Dickinson conclui o poema com ironia, pois, paradoxalmente, os fatores destinados a saciar a fome da narradora são os mesmos que inibem o seu apetite. (POLLAK, 1984, p. 129) Ainda como Fernando Pessoa, a poeta ama a poesia que vem da irrealização.

"The Poets light but Lamps" representa um momento importante no desenvolvimento da teoria poética de Dickinson:

\begin{tabular}{|c|c|}
\hline $\begin{array}{l}\text { The Poets light but Lamps- } \\
\text { Themselves - go out- } \\
\text { The Wicks they stimulate- } \\
\text { If vital Light }\end{array}$ & $\begin{array}{l}\text { O Poeta acende Lâmpadas - } \\
\text { Ele próprio apaga-se - } \\
\text { Os Pavios que inflama - } \\
\text { Se têm Essência }\end{array}$ \\
\hline $\begin{array}{l}\text { Inhere as do the Suns - } \\
\text { Each Age a Lens } \\
\text { Disseminating their } \\
\text { Circumference- }\end{array}$ & $\begin{array}{l}\text { Como os Astros agregam-se } \\
\text { Uma Lente em cada Época } \\
\text { Disseminando a sua } \\
\text { Circunferência - }\end{array}$ \\
\hline J 883 F 930 & Trad. José Lira (2006, p. 150) \\
\hline
\end{tabular}

O advérbio "apenas" (but) do primeiro verso já aponta para o contraste central do poema (ANDERSON, 1960, p. 58): as lâmpadas da primeira estrofe, representando a luz terrestre, em oposição aos sóis da segunda, que simbolizam a luz celestial; ou ainda, as lâmpadas ("verdades poéticas") do universo particular da poeta, opondo-se ao universo planetário iluminado pelo sol. Em decorrência disso, a perenidade da arte se sustém, apesar do caráter efêmero do seu criador. 
A ironia situacional manifesta-se logo nos dois primeiros versos. A partir daí, Dickinson vai estabelecendo uma relação entre ela, como poeta, o poema e o leitor. Trata-se de mais um dos poemas em que Dickinson toma um emblema casual, para aprofundar o seu significado simbólico por meio de imagens originais (ST. ARMAND, 1984, p. 354).

Dickinson trata poeticamente da preocupação com a fama e do contraste entre a brevidade da vida humana com a perenidade da poesia; esta, não o poeta, merece reconhecimento eterno (THACKREY, p. 35-37). O pavio aceso pode representar a vida mortal do poeta bem como o próprio poema que ele produz. No primeiro caso, a luz do pavio estaria representando a precariedade da vida humana em oposição à permanência da obra poética; no segundo, representaria o próprio poema, pavio aceso pelo poeta, que serão disseminados pela lente, em círculos contínuos e infindáveis. Os pronomes "eles" do segundo verso e "deles" do sétimo mostram que no fim a circunferência dos poetas e a dos poemas se encontrarão (GELPI, 1975, p. 299). E caberá então a cada época, com a sua ótica, reconhecer a verdadeira poesia.

Em "There is a solitude of space" verificamos um contingenciamento do infinito:

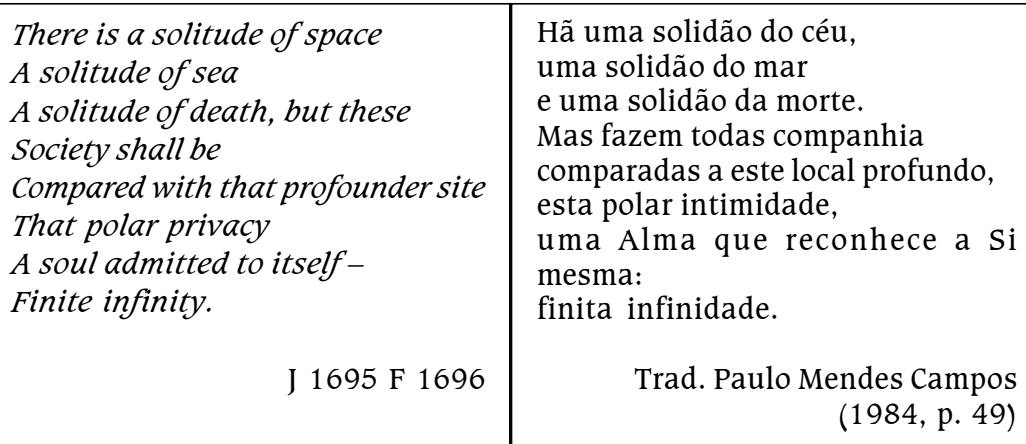

Esta típica experiência americana, "o isolamento metafísico", da qual Dickinson participou, deu origem ao que há de melhor em poesia. (ROVIT ${ }^{7}$, apud DUCHAC, p. 513) Este poema realça a tranquilidade íntima da alma que se voltou para si mesma, após ter se projetado contra o espaço exterior. A "polar intimidade" corresponde à solidão extrema, pela qual a alma retorna ao lar, depois de ter se surpreendido num contexto indefinido.

Este poema, pela situação existencial que dramatiza, leva-nos à ironia metafísica, de que trataremos em outra oportunidade.

133, 1961.

\footnotetext{
${ }^{7}$ ROVIT, Earl H. The Shape of American Poetry. Jahrbuch Für Amerikastudien, v. 6, p. 122-
} 


\title{
RESUMO
}

A poesia de Emily Dickinson (1830-1886) contempla vários tipos de ironia: a autoironia, quando a poeta se volta para si mesma; a visão irônica do mundo, quando trata de alguns aspectos externos da existência (saber humano, sistema de crenças, natureza, sociedade e situação); ironia metafísica, quando, ao mesmo tempo, reflete sobre os mistérios do cosmos e do seu universo cultural. Com maior ou menor ênfase, os seus temas fundamentais (amor, fé, morte, sofrimento) comparecem em todas as modalidades de ironia, quer como intenção, quer como recurso mobilizado para produzir o efeito irônico. Assim, neste trabalho, pretendemos fazer um dos possíveis recortes em sua obra, ou seja, trataremos da ironia situacional, que se manifesta em muitos poemas, como os analisados neste trabalho.

Palavras-chave: Dickinson; Ironia; Poesia americana; Tradução poética.

\begin{abstract}
The poetry of Emily Dickinson (1830-1886) contemplates several kinds of irony: self-irony in the poems aimed at herself; ironical world vision, when she deals with some external aspects of existence (human knowledge, system of beliefs, nature, society, and situation), metaphysical irony when she reflects on the mysteries of the cosmos and of her cultural universe. With varying degrees of emphasis, her fundamental themes (love, faith, death, suffering) are present in all kinds of irony, either as an intention or as a device designed to produce an ironical effect. This is thus an attempt to make one of the possible selections from her work, namely, to tackle the situational irony present in many of her poems like the ones hereby analyzed.

Keywords: Dickinson; Irony; American poetry; Poetry translation.
\end{abstract}

\section{REFERÊNCIAS}

ALEXANDER, Char1otte.The Poetry of Emily Dickinson. New York: Monarch press, 1965. ANDERSON, Char1es. R. Emily Dickinson's Poetry, Stairway of Surprise. New York: Ho1t, Rinehart and Winston, 1960.

BALDI, Sergio. The poetry of Emi1y Dickinson (1956). Sewanee Review, 68, n. 3. (Ju1y- 
September/Summer 1960, p. 438-449.

BEnder, Ivo. (Trad.) Poemas de Emily Dickinson. Porto Alegre: Mercado Aberto, 2002.

CAMPoS, Paulo. Mendes. de. Oito Poemas/Emily Dickinson (1969), Trinca de Copas. Rio de Janeiro: Achiamé, 1984, p. 47-50.

CHASE, Richard. Emily Dickinson. New York: William Sloane, 1951.

CODY, John. After Great Pain: The Inner Life of Emily Dickinson. Harvard University Press, 1971.

. J 252, The Explicator, 37, 1. (Fall 1978, p. 15-16;

DAGHLIAN, Carlos; CHOCIAY, Rogério. E. Poems by Emi1y Dickinson in Portuguese: Trans1ation and Bib1iographical Notice, Higginson Journal, n. 43. (2nd ha1f 1985, p. 3-13.

. A Obsessão Irônica na Poesia de Emily Dickinson. Tese de Livre-Docência. São José do Rio Preto, SP, UNESP, 1987. [As traduções de Carlos Daghlian incluídas nesta tese contaram com a colaboração de Rogério E. Chociay]

DICKINSON, Emily. The Complete Poems. Thomas H. Johnson (Ed.). Cambridge, Mass.: Harvard University Press, 1955.

DICKINSON, Emily. The Letters of Emily Dickinson I. Thomas H. Johnson (Ed.). Cambridge, Mass.: Harvard University Press, 1965.

The Poems of Emily Dickinson. Ralph W. Franklin (Ed.). Cambridge, Mass.: Harvard University Press, 1999.

DIEHL, Joanne. Feit. Dickinson and the Romantic Imagination. Princeton University Press, 1981.

DUCHAC, Joseph. The Poems of Emily Dickinson (an annotated guide to commentary in English, 1890-1977). Boston: G. K. Hall, 1979.

FARIA, Idelma. Ribeiro. de. (Trad.) T. S. Eliot, Emily Dickinson, René Depestre. São Paulo: Hucitec, 1992.

FERLAZZO, Paul. Emily Dickinson. Boston: Twayne, 1976.

GELPI. The Tenth Muse: The psyche of the American Poet. Harvard University Press, 1975.

Gomes, Aíla. de Oliveira.. (Trad.). Emily Dickinson: Uma Centena de Poemas. São Paulo: T. A. Queiroz / EdUSP, 1985

GRIFFITH, C1ark. The Long Shadow: Emily Dickinson's Tragic Poetry. Princeton Univ. Press, 1964.

HOWARD, William. In: WALCUTT, Charles. Child; J. Edwin. Whitesell. (Eds.). Explicator Cyclopedia: Modern poetry. (1942-62) Chicago: Quadrangle Books, v. 1. 1966; p. 64.

JUHASZ, Suzanne. 'I Dwell in Possibility': ED in the Subjunctive Mood. Emily Dickinson Bulletin, n. 32. (Second Half 1977, p. 105-109.

The Undiscovered Continent: Emily Dickinson and the Space of the Mind. Bloomington, Bloomington: Indiana University Press, 1984.

KHER, Inder. Nath. The Landscape of Absence; Emily Dickinson's Poetry. Ya1e University Press, 1974.

LAIR, Robert. L. Barron's Book Notes: A Simplified Approach to Emily Dickinson. Woodbury, N.Y.: Barron's Educational Series, 1971.

LIRA, José. (Trad.) Emily Dickinson: Alguns Poemas. São Paulo: Iluminuras, 2006. 
MINER, Earl. Roy. [J] 287. In: WALCUTT, Charles. Child ; WHITESELL, J. Edwin,. (Eds.). Explicator Cyclopedia, Modern poetry.(1942-62) Chicago: Quadrangle Books, v. 1. 1966, p. 57-58.

MOREY, Frederick. L. The Fifty Best Poems of Emi1y Dickinson (a three chapter study). ED Bulletin, n. 25. (1st ha1f 1974, p. 5-23.

MOSSBERG, Barbara. Antonina. C1arke. Emily Dickinson's Nursery Rhymes. In: JUHASZ, Suzanne,. (Ed.). Feminist Critics Read Emily Dickinson. Indiana University. Press, 1983.

PERRINE, Laurence. There's a certain Slant of light. In: 14 by Emily Dickinson. Thomas M. Davis (Ed.). Chicago: Scott, Foresman, 1964, p.34-35.

PESSOA, Fernando. Trapo (1930). In: CAMPOS, Álvaro. de. Campos, Ficções do Interlúdio. Obra Poética. Rio de Janeiro: Aguilar, 1960.

PICKARD, John. B. Emily Dickinson, An Introduction and Interpretation. New York: Barnes and Noble, 1967.

POLLAK, Vivian. R. Dickinson: The Anxiety of Gender. Cornell University Press, 1984.

PORTER Dickinson: The Modern Idiom. Cambridge, Mass.: Harvard University Press, 1981.

RENAULT, Abgar. Poesia: Tradução e Versão. Rio de Janeiro: Record, 1994, p. 31 - 35.

SENA, Jorge. de. 80 Poemas de Emily Dickinson Lisboa: Edições 70, 1978.

SHERWOOD, Wi11iam. R. Circumference and Circumstance: Stages in the Mind and Art of Emily Dickinson. Co1 umbia University Press, 1968.

ST. ARMAND, Barton. Emily Dickinson and Her Culture: The Soul's Society. Cambridge University. Press, 1984.

THACKREY, Donald. E. Emily Dickinson's Approach to Poetry. Lincoln: University of Nebraska, 1954. Excerpted: DAVIS, Thomas. M. (Ed.), 14 by Emily Dickinson. Chicago: Scott, Foresman, 1964, p. 35-37.

VIZIoli, Paulo. (Trad.) Emily Dickinson, Poetas Norte-Americanos: Antologia Bilíngüe. Rio de Janeiro: Lidador, 1976, p. 40-44.

WARREN, Austin. Connections. University of Michigan Press, 1970.

WOLFF. Emily Dickinson. New York: Alfred Knopf, 1986.

Submetido em: 27/04/2009

Aceito em: 10/08/2009 